Н. В. Полякова

Байкальский государственный университет, г. Иркутск, Российская Федерация

В. Е. Залешин

г. Иркутск, Российккая Федерация

\author{
ОЦЕНКА РИСКА ВЫВОДА НОВОЙ УСЛУГИ НА РЫНОК \\ НА ОСНОВЕ ВЫЯВЛЕНИЯ СКРЫТЫХ ПОТРЕБНОСТЕЙ ПОКУПАТЕЛЕЙ
}

\begin{abstract}
АНнОтАЦИЯ. Статья посвящена разработке методики определения скрытых потребностей покупателей, результаты применения которой могут служить предпосылкой характеристики и оценки риска выведения производителем (поставщиком) новых услуг на рынок. Исходным положением методики является предположение о том, что потребности человека удовлетворяются не только за счет функциональных характеристик продукта. В настоящее время население все больше предъявляет к товарам и услугам также требования социального и эмоционально-психологического характера. Удовлетворение комплекса потребностей покупателя связано для поставщика с риском, порой значительным, поскольку определяет объемы продаж новых для рынка услуг или товаров. Авторы исходят из предположения, что риск вывода продукта на рынок является своего рода отражением требований потребителей. Значит, этот риск может быть оценен суммой рисков действия как функциональных, так и социальных и эмоционально-психологических факторов удовлетворения потребителей. В связи с этим разработана система критериев оценки выделенных групп риска принятия потребителем нового продукта при его выведении на рынок, а также алгоритм расчета интегрального риска. Приводятся обоснование и описание сущности методики оценки риска вывода нового продукта на рынок, а также результат ее апробации - разработанная программа исследования скрытых потребностей покупателей услуг мобильной связи оператора Tele2 в Иркутской области и расчет уровня риска вывода новой услуги компании на рынок. кЛючЕВЫЕ СЛОВА. Риск вывода продукта на рынок; новый продукт; скрытая потребность; пассивная потребность.

ИНФОРМАЦИЯ О СТАТЬЕ. Дата поступления 27 ноября 2015 г.; дата принятия к печати 25 декабря 2015 г.; дата онлайн-размещения 29 января 2016 г.
\end{abstract}

\author{
N. V. Polyakova \\ Baikal State University, \\ Irkutsk, Russian Federation \\ V. E. Zaleshin \\ Irkutsk, Russian Federation
}

\title{
ASSESSING RISKS OF A NEW SERVICE MARKET LAUNCH ON THE BASIS OF IDENTIFYING CUSTOMERS' HIDDEN REQUIREMENTS
}

\begin{abstract}
The article is devoted to developing methods of identifying customers' hidden requirements. The results of its use can serve as a pre-condition of the characteristic and assessment of the risk of launching new services on the market by the producer. A starting point of these methods is a supposition that human requirements are satisfied not only by functional characteristics of the product. At the present moment, people more than ever apply social and emotional-psychological requirements to goods and services. Satisfying the buyers' requirement package is connected with risks for suppliers, sometimes very considerable, for the supplier determines the sales volume of new market services or goods. The authors assume that the risk of product market lunch is a sort of reflection of consumers' requirements. Thus, this risk can be assessed by the sum of risks of both functional and social and emotional-psychological
\end{abstract}

(C) Н. В. Полякова, В. Е. Залешин

\section{Baikal Research Journal}


factors of satisfying the customers. In this connection, the article presents development of a criteria system for assessing specified groups of the risks in customers' accepting a new product while launching it on the market as well as an algorithm of integral risk calculation. It substantiates and describes the essence of methods of assessing the risks of the new product market launch, as well as the results of its approbation in the form of a program developed for investigating the requirements of the buyers of the mobile communication Tele 2 operator' services in Irkutsk Oblast and of calculation of risk levels in the company's new service market launch.

KEYWORDS. Risk of new product market launch; new product; hidden requirement; passive requirement.

ARTICLE INFO. Received November 27, 2015; accepted December 25, 2015; available online January $29,2015$.

В процессе выведения нового продукта на рынок особое значение для производителя (поставщика) приобретает задача оценки величины риска его принятия потребителями.

Вообще риск вывода нового продукта на рынок определяется целым рядом составляющих: уровнем конкуренции на данном рынке, степенью адекватности ценовой политики, организацией системы продаж и другими маркетинговыми инструментами. Однако следует признать, что ключевой составляющей риска является степень удовлетворения потребностей покупателей, т. е. выгодами (ценностью), заложенными для него в новом товаре или услуге. При этом чрезвычайно важно понимание производителем (поставщиком) не только явных, но и скрытых / пассивных потребностей людей, которым предлагается продукт.

Проблема активизации скрытых и пассивных потребностей становится актуальной при разработке и реализации мероприятий по выведению нового продукта на рынок. Трудности, связанные с решением указанной проблемы, могут оказывать влияние на скорость процесса распространения новинки. Точность в выявлении скрытой либо пассивной потребности может влиять на степень риска при выведении продукта на рынок.

В связи с этим данная статья посвящена исследованию скрытых потребностей покупателей с целью оценки риска выведения продукта на рынок.

Методологические основы исследования потребностей и рисков вывода на рынок новых продуктов. Для обеспечения успеха компании при выведении продукта на рынок необходимо уметь выявлять новые потребности текущих и потенциальных клиентов и соотносить с ними свои предложения. При этом новые потребности могут и не выражаться явно, а их определение может быть весьма затруднительным.

Другими словами, мы говорим о скрытых потребностях, выявление и более быстрое по сравнению с конкурентами удовлетворение которых является залогом успешной деятельности компании на современных рынках.

Дж. О’Шонесси, признанный специалист в области активизации скрытых и пассивных потребностей, приводит следующую классификацию:

- активные потребности;

- пассивные потребности;

- скрытые потребности [1].

К активным относятся явно выраженные потребности, которые производитель или поставщик продукта корректно определяет и способен удовлетворить практически полностью. В реальной жизни очень мало примеров полного удовлетворения потребностей покупателей. На практике поставщики стараются лишь отвечать ожиданиям своих клиентов и по возможности превосходить их. При этом возможны три исхода:

- потребность в определенной степени не удовлетворена;

\section{Baikal Research Journal}

электронный научный журнал Байкальского государственного университета 
- потребность удовлетворена полностью;

- предложение компании развивает потребности клиента, поскольку в определенной степени превосходит уровень его ожиданий.

К пассивным относятся те потребности, которые сами по себе не являются причинами покупательского поведения. Потребность в продукте в данном случае - недостаточное условие для его покупки. Основным фактором возникновения пассивной потребности, по нашему мнению, является информационная среда продукта, т. е. совокупность сведений о свойствах, особенностях, преимуществах и ограничениях использования продукта. Когда человек сопоставляет всю имеющуюся у него информацию о продукте, возможны ситуации сомнения в целесообразности приобретения, откладывания покупки на «потом», наконец, игнорирования этой потребности. Все подобные ситуации и характеризуются как проявление пассивной потребности.

Скрытые потребности, по Дж. О’Шонесси, - это тот случай, когда: «потребители могут не осознавать, не ощущать потребности в продукте, но могли бы ее почувствовать, если бы узнали, как он способен улучшить их жизнь» [1]. Из приведенного определения можно сделать вывод: природа скрытой потребности связана с информационной средой продукта. Действительно, если человек не знает, чего он хочет, значит, он не располагает никакой информацией. Если человек знает, чего он хочет, но не знает, каким образом существующий продукт может улучшить его жизнь, значит, он не располагает информацией о дополнительных свойствах продукта, его новых преимуществах и новых способах использования [2].

Определение Дж. О'Шонесси также указывает на интересное и полезное для производителя (поставщика) свойство скрытой потребности: ее можно активизировать. При выведении нового продукта на рынок (при улучшении существующего) необходимо создать соответствующую информационную среду и тем самым стимулировать в сознании потенциального потребителя представление о ценности реального обладания или использования продукта и, таким образом, преобразовать скрытую потребность в явную, т. е. активную.

В целом, все случаи проявления скрытых потребностей, на наш взгляд, можно охарактеризовать двумя ситуациями:

- человек не знает, чего он в принципе хочет - аналог скрытой потребности по Дж. О’Шонесси;

- человек знает, чего он хочет, но не делится своей информацией с теми, кто может дать ему это (производителем или поставщиком) - аналог пассивной потребности по Дж. О’Шонесси.

Считаем также необходимым уточнить понятие «новый продукт». Западные специалисты подразделяют продукты по степени новизны на следующие категории:

1. Новый для мира (мирового рынка) продукт - крупное достижение, которое создает полностью новый рынок, меняет существующее поведение покупателей.

2. Новые линии продуктов - являются новыми для компании, но не для рынка. Это - первый выход продуктов компании на существующий рынок.

3. Дополнения к существующим линиям продуктов - расширение текущей линии продуктов.

4. Совершенствование существующих продуктов - ведет к заметному улучшению свойств продуктов (увеличению ценности) или замене существующих товаров более совершенными.

5. Продукты после процедуры перепозиционирования - продукты, которые нацелены на новый сегмент рынка или позиционированы для нового использования или применения.

6. Продукты с сокращенной стоимостью - продукты, которые обеспечивают идентичные выгоды потребителей по более низкой цене [3; 4].

\section{Baikal Research Journal}


Для целей нашего исследования предлагаем выделить только две категории продуктов по степени новизны:

- новый для мира продукт, или «абсолютная новинка»;

- «модификация существующего продукта» .

Дело в том, что, опираясь на определения, предложенные Дж. О’Шонесси, можно утверждать: производитель (поставщик) сталкивается с проявлениями как скрытых, так и пассивных потребностей при выведении на рынок товара или услуги любой степени новизны. Значит, нет необходимости в столь «дробной» классификации, и категории 2-6 с той или иной степенью допущения можем называть «модификацией существующего продукта». Деление же новых продуктов на категории «абсолютная новинка» и «модификация» следует признать принципиальной, поскольку разработка нового для мира продукта происходит на основе достижений научно-технического прогресса и требует другого (более масштабного) подхода к определению и исследованию группы потенциальных потребителей.

Итак, в нашем исследовании скрытых / пассивных потребностей покупателей для целей выведения на рынок под новым продуктом будем понимать «модификацию существующего продукта». Вторым ограничением настоящего исследования является рассмотрение рынка потребительских товаров и услуг.

Итак, модификация существующего продукта должна соответствовать основным требованиям потребителя, в числе которых можно выделить:

- функциональные - требования непосредственно к свойствам, характеристикам и способам потребления;

- социальные - требования, опосредованные влиянием окружения, в котором находится потребитель. Это требования, диктуемые нормами и ценностями различных социальных групп, к которым принадлежит потребитель или стремится принадлежать;

- эмоционально-психологические - требования, опосредованные настроением, эмоциями, которые должен вызывать продукт, чтобы обеспечить человеку устойчивое душевное состояние [5;6].

Фактически все изложенные требования к новому продукту и есть скрытые или пассивные потребности. В идеале удовлетворяться эти требования должны комплексно.

Обратимся к рассмотрению проблемы оценки величины риска, связанного с выведением нового товара или услуги на рынок.

Некоторые авторы, например, Е. Башкирова, Е. Данилюк, определяют всего два критерия оценки подобного риска:

- масштаб потерь в случае неудачного продвижения продукта;

- возможный размер прибыли в случае удачного продвижения продукта [7].

Такой подход в настоящее время является слишком узким и не может удовлетворять решению задачи оценки риска нового продукта при выходе на рынок. На самом деле приведенные критерии отражают действие только одного фактора риска, а именно качества разработки и реализации программы продвижения, в то время как ключевые факторы успеха (провала) не учитываются.

Попытаемся определить факторы риска вывода нового продукта. Как было уже показано, для того, чтобы стать успешным на рынке, новый продукт (или модификация существующего продукта) должен соответствовать основным требованиям потребителя, а именно обеспечивать достаточную степень удовлетворения функциональных, социальных и эмоционально-психологических потребностей. Они же могут быть как явными, так и скрытыми / пассивными. Таким образом, можно утверждать, что основными составляющими риска вывода нового продукта являются:

- функциональный риск;

\section{Baikal Research Journal}


- социальный риск;

- эмоционально-психологический риск.

Каждый из перечисленных видов риска определяется набором присущих ему факторов.

К факторам функционального риска ${ }^{1}$ относятся следующие:

1. Ценность атрибутов. Критерием оценки данного фактора может быть континуум «максимально высокая оценка покупателями новых атрибутов продукта минимальная оценка покупателями новых атрибутов продукта» .

2. Уникальность атрибутов. Оценка фактора может производиться по следующей шкале:

- новый продукт предлагает выгоды, единственные в своем роде (в том числе подтвержденные наличием бренда);

- продукт обезличен (конкуренты легко могут скопировать его);

- имеющиеся на рынке конкурирующие продукты предлагают идентичные выгоды.

3. Своевременность появления. Критерием оценки данного фактора может быть континуум «позднее появление на рынке - раннее появление на рынке (рынок не готов к восприятию нового продукта)».

4. Эффективность производства. В качестве критериев оценки предлагается, во-первых, континуум «скорость разработки и выведения нового продукта на рынок высокая - скорость разработки и выведения нового продукта на рынок низкая»; во-вторых, такие экономические показатели, как рост / уменьшение затрат на разработку и производство по сравнению со «старыми» продуктами, а также рост / уменьшение прибыли от реализации по сравнению со «старыми» продуктами.

5. Эффективность маркетинга. Критериями оценки здесь являются:

- размер доли рынка;

- наличие / отсутствие дифференцирования продукта;

- уровень соответствия / приемлемости цены финансовым возможностям целевой группы потребителей;

- показатели эффективности системы распределения;

- показатели эффективности программы продвижения и др.

Факторы 4 и 5 относятся скорее к внутренней деятельности компании, поэтому оценку данных факторов лучше производить на основе анализа документации и опроса персонала компании, а не выносить ее на «суд» внешних аудиторий.

К факторам социального риска относятся следующие:

1. Принадлежность к социальной группе, члены которой разделяют ценность обладания (пользования) выводимым продуктом или его аналогами. Критериями оценки здесь могут быть следующие континуумы:

- «членство в группе (или желание присоединиться к группе) - автономия»;

- «дружеские связи с членами группы (или стремление к ним) - отказ от сближения с людьми»;

- «желание завоевать (сохранить) привязанность членов группы - психологическая независимость»;

- «верность в дружбе - действия соответственно личным побуждениям» и др.

2. Уважение к другим людям. В качестве критериев оценки предлагаются континуумы:

- «восхищение людьми с высоким статусом - неуважительное отношение к людям с высоким статусом»;

- «уважение к людям с равным статусом - неуважительное отношение к людям с равным статусом»;

${ }^{1}$ При разработке факторов функционального риска использованы положения П. Дойля [8].

\section{Baikal Research Journal}


- «уважение к людям с низким статусом - неуважительное отношение к людям с низким статусом» и др.

3. Подчинение / доминирование. Критериями оценки могут быть континуумы:

- «стремление контролировать поведение других людей - стремление быть под опекой и руководством других людей»;

- «активность в контактах с людьми - пассивность в контактах с людьми»;

- «стремление к освобождению от регламентированных отношений - подчинение системе регламентированных отношений»;

- «согласие быть ответственным за деятельность и безопасность других людей - избегание ответственности за деятельность и безопасность других людей» .

4. Отношение к успеху / неудаче. Критериями оценки выступают континуумы:

- «стремление к успеху - избегание неудачи»;

- «стремление делать что-то лучше других - уклонение от трудностей»;

- «настойчивость в устранении помех на пути к цели - подчинение внешним обстоятельствам»;

- «приоритет достижения успеха любой ценой - приоритет сохранения имеющихся ресурсов и достижений».

5. Эгоизм / альтруизм. Критериями оценки могут быть континуумы:

- «приоритет защиты личных интересов - приоритет заботы о другом человеке (людях)»;

- «стремление к самореализации в личных достижениях - стремление сделать мир лучше для всех» и др.

Факторы эмоционально-психологического риска и критерии их оценки:

1. Отношение человека к окружающему миру. Критерием оценки может быть континуум «окружающий мир вызывает положительные эмоции - окружающий мир вызывает отрицательные эмоции» .

2. Отношение человека к самому себе. Критерием оценки является континуум от ощущения «есть счастье в жизни» до «нет счастья в жизни» .

3. Характер действия эмоциональных раздражителей (например, рекламы). Критерием оценки может быть шкала:

- положительные эмоции;

- нейтральные эмоции;

- отрицательные эмоции.

Такова система критериев, предлагаемая нами для оценки риска нового продукта при его выведении на рынок. Далее раскроем суть разработанной методики исследования скрытых / пассивных потребностей покупателей для целей выведения модификации существующего продукта на потребительский рынок. Ее основные положения заключаются в следующих пунктах:

1. Скрытые / пассивные потребности отождествляются с требованиями потребителя к модификации существующего продукта.

2. Модификация продукта должна соответствовать требованиям потребителей по следующим аспектам: функциональные требования; социальные требования; эмоционально-психологические требования.

3. Допускается существование определенного риска, связанного с удовлетворением указанных в п. 2 требований потребителя, как интегрального показателя риска нового продукта при выведении на рынок.

4. Интегральный показатель риска формируют следующие факторы: функциональный риск; социальный риск; эмоционально-психологический риск.

5. Для определения значения выделенных факторов рисков разрабатывается система критериев оценки.

\section{Baikal Research Journal}


6. Для факторов частных рисков и интегрального риска определяются граничные значения.

7. Разрабатывается инструментарий для измерения переменных, характеризующих частные риски, и проводится исследование с целью получения оценок факторов риска.

8. Полученные оценки сравниваются с граничными значениями по принципу: «ниже - хорошо», «выше - плохо». Факторы риска, получившие оценки, превышающие граничные значения, указывают на выявленную скрытую / пассивную потребность.

9. Полученные оценки факторов суммируются для нахождения интегрального показателя риска. Если итоговое значение лучше граничного, то данную модификацию продукта можно рекомендовать к выведению на рынок. Если итоговое значение хуже, то даются рекомендации о целесообразности закрытия проекта.

Оценка уровня риска выведения новой услуги на рынок. Проиллюстрируем работу описанной методики на примере разработки программы исследования скрытых потребностей потребителей услуг мобильной связи оператора Tele2 в Иркутской области.

В соответствии с предлагаемой методикой скрытые потребности отождествляются с определенными требованиями человека к услугам мобильной связи. Удовлетворение этих требований сопряжено с риском. Ведь услуги могут быть как приняты рынком, так и отвергнуты им. Следовательно, оценка риска выхода Tele 2 на рынок с пакетом новых услуг будет отражать вероятность актуализации скрытых потребностей потребителей (превращения их в действующие). Таким образом, практическая цель исследования - оценка риска, или вероятности успеха / неуспеха выведения модифицированных услуг сотовой связи Tele2 на рынок Иркутской области.

В ходе исследования необходимо придерживаться следующей схемы:

1. Характеристика текущего состояния исследуемого продукта (до модификации) [9].

2. Описание предлагаемых улучшений продукта в соответствии с гипотезами исследования [10].

3. Исследование по методике бренд-мэппинга [11-13]. Данное исследование поисковое, поэтому опрос проводится на небольшой выборке, сформированной невероятностным методом по принципу удобства для исследователя. В результате должны быть получены оценки факторов риска выведения новых услуг на рынок.

4. Оценки факторов риска, полученные в результате, суммируются и определяется величина обобщающего (интегрального) риска. Здесь же производится расчет средних значений факторов риска и интегрального риска.

5. Определение граничных значений для факторов риска. Если значение показателя интегрального риска превышает допустимую граничную величину, то делается вывод о выявленной скрытой потребности. При этом до нахождения способов удовлетворения этой потребности вывод существующего продукта на рынок признается нецелесообразным.

6. Анализ влияния факторов риска на интегральный показатель. Цель анализа - определить «тревожные» зоны на уровне отдельных составляющих риска выведения нового продукта на рынок для выявления скрытых потребностей в отношении не услуги Tele2 в целом, а ее отдельных компонентов.

Для определения факторов риска на основе предложенной системы критериев оценки применили следующие группы переменных:

1. Функциональные (11 переменных) - отражают функциональные требования пользователей услуг оператора:

\section{Baikal Research Journal}


- качество голосовой связи - может принимать значения в диапазоне от «низкое качество» до «высокое качество»;

- качество дополнительных услуг, предоставляемых оператором - может принимать значения в диапазоне от «низкое качество» до «высокое качество»;

- скорость мобильного интернета - принимает значения в диапазоне от «низкая скорость» до «высокая скорость»;

- специфичность (особость) выгод, получаемых при пользовании услугами Tele2 - значения в диапазоне от «имеющиеся на рынке конкурирующие услуги предлагают идентичные выгоды» до «выгоды, единственные в своем роде»;

- уникальность тарифных планов - значения в диапазоне от «тарифы такие же, как у других операторов» до «тарифы уникальные, не воспроизводимые конкурентами»;

- своевременность появления на рынке - значения в диапазоне от «рынок не готов к восприятию новых услуг» до «рынок готов к восприятию новых услуг»;

- доля рынка - значения в диапазоне от «малая» до «большая»;

- дифференцирование услуг - значения в диапазоне от «предложение единственной услуги» до «компания предлагает портфель услуг»;

- цена услуги - значения в диапазоне от «высокая, или неприемлемая, цена» до «соответствующая, или приемлемая, цена»;

- система распределения - значения в диапазоне от «неэффективная» до «эффективная»;

- качество рекламной кампании - может принимать значения в диапазоне от «низкое качество» до «высокое качество».

2. Социальные переменные (8 переменных) - отражают социальные требования потребителей услуг мобильной связи:

- принадлежность к социальной группе - значения от «автономия» до «присоединение к группе»;

- установление дружеских связей - значения от «отказ от сближения с человеком» до «дружеские связи с людьми»;

- самоутверждение в коллективе - значения от «завоевание привязанности людей» до «независимость»;

- уважение к другим людям - значения от «избавление, отказ от общения с другими, игнорирование других, пренебрежение людьми, обман» до «восхищение другими»;

- подчинение / доминирование - значения от «быть тем, кого опекают, поддерживают, окружают заботой, защищают, любят, дают советы, кем руководят, кого прощают, утешают» до «контроль над поведением других, главная роль в контактах»;

- отношение к успеху / неудаче - значения от «избегание неудачи» до «достижение успеха, реализация своих талантов»;

- целеустремленность - значения от «отсутствие инициативы» до «настойчивость в устранении помех на пути к цели»;

- эгоизм / альтруизм - значения от «защита и отстаивание своих интересов» до «оказание помощи, проявление заботы, забвение собственных интересов ради интересов другого человека» .

3. Эмоционально-психологические переменные (3 переменные) - отражают эмоционально-психологические требования потребителей:

- отношение человека к окружающему миру - значения от «окружающий мир вызывает отрицательные эмоции» до «окружающий мир вызывает положительные эмоции»;

- отношение человека к самому себе - значения от «нет счастья в жизни» до «есть счастье в жизни»;

\section{Baikal Research Journal}


- характер действия эмоциональных раздражителей - значения от «вызывают отрицательные эмоции» до «вызывают положительные эмоции» .

Для сбора первичных данных в настоящем исследовании применяется технология бренд-мэппинга [12]. В нашем случае строится система координат, по осям которых откладываются значения переменных, отражающих требования потребителей: по вертикальной оси $у$ задается функциональная переменная, по горизонтальной оси $x$ - социальная / эмоционально-психологическая переменная (рис.).

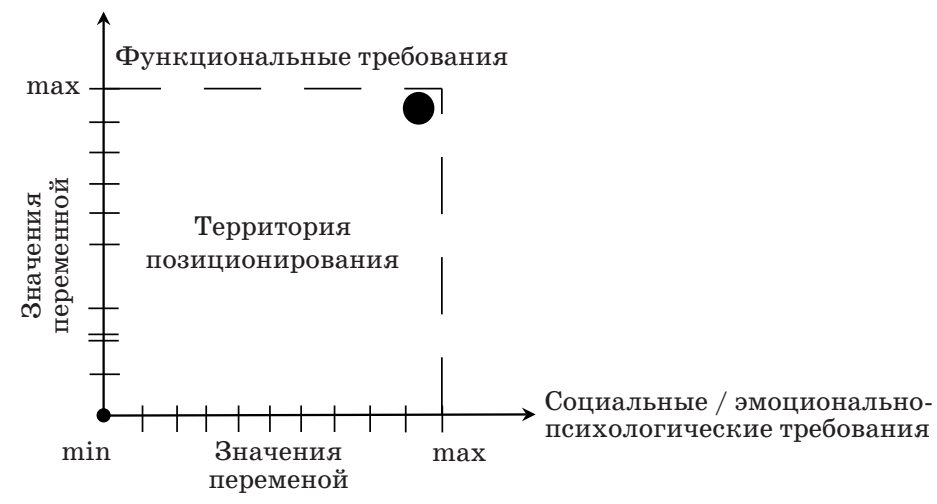

Оиенка переленных (требований потребителя) при полощи технологии бренд-лэппинга

Все переменные группируются попарно. Для каждой переменной формулируется соответствующий вопрос. В одной системе координат респондентом дается один ответ сразу на два вопроса (см. рис., черный кружок). Местоположение кружка на координатном поле определяет степень удовлетворения одной функциональной и одной социальной / эмоционально-психологической потребности. Чем выше эта степень, тем ниже уровень риска, связанного с удовлетворением данной потребности. Наоборот, чем ближе кружок расположен к началу координат, тем в меньшей степени удовлетворяются данное функциональное и социальное / эмоционально-психологическое требования потребителя к продукту. Это означает более низкую оценку характеристик продукта, соответствующих указанным требованиям, т. е. более высокий риск удовлетворения данных требований. Другими словами, местоположение ответа респондента, близкое к началу координат, означает неудовлетворенную потребность человека относительно исследуемых характеристик продукта. Потребность не удовлетворена, потому что о ее существовании поставщик услуг до сих пор ничего не знал. Значит, это скрытая потребность, которую удалось выявить.

Рассмотрим, как формулируются вопросы для респондентов при проведении исследования скрытых потребностей абонентов Tele2. В одном вопросе кодируется одна переменная. Значит, необходимо разработать вопросы в количестве используемых в исследовании переменных, причем каждый вопрос с вариантами ответов должен адекватно инструментализировать (отражать) соответствующую переменную. Например, переменной «качество голосовой связи (значения от “низкое качество” до “высокое качество”)» соответствует вопрос «Как часто у Вас обрывается связь во время разговора?» с вариантами ответов в диапазоне от «постоянно» до «никогда».

Для анализа собранной информации применяется методика оценки риска выведения на рынок нового продукта. Предварительно подготавливается шаблон для расчета факторов риска на основе той же системы координат для бренд-мэппинга. Карта шаблона отличается от бренд-карты наличием цены делений и координатной сетки.

\section{Baikal Research Journal}

электронный научный журнал Байкальского государственного университета 
Состоянию системы, когда риск минимален или отсутствует, соответствует значение 0 [14]. Это означает, что скрытая потребность не выявлена. Максимальному риску соответствует значение 1 [14], что означает выявленную скрытую потребность относительно конкретной характеристики продукта. Значение факторов увеличивается при движении к началу координат.

В разработанном для исследования опроснике для каждого вопроса сформулированы крайние варианты ответов. Полученные ответы отражают отношение респондента к определенной характеристике продукта - от явно негативного до явно позитивного. Таким образом, любая точка на оси координат попадает в интервал между отрицательной и положительной оценками, а перейти от «минуса» к «плюсу» (или наоборот) можно только через ноль, который является выражением нейтрального отношения человека к характеристике продукта. В нашей системе координат нейтральное отношение (оно соответствует умеренному риску) находится в середине интервала между крайними значениями. В предлагаемой системе измерения такому положению соответствует значение риск-фактора, равное 0,5 - граничное значение для любого частного фактора риска. Если значение ниже, то продукт имеет шансы быть признанным потребителями. Если же фактическая оценка фактора окажется более 0,5 , то с такой характеристикой продукт на рынок выводить нецелесообразно.

В нашем исследовании для каждой переменной максимальное значение фактора риска равно 1 , минимальное -0 , граничное значение $-0,5$. Для получения более адекватных оценок рассчитываются средние значения показателей риска. В нашем случае такое значение для всей изучаемой группы потребителей составило 0,49. Группировка полученных результатов для 38 респондентов-потребителей услуг мобильной связи оператора Tele2 в зависимости от пола и возраста наглядно демонстрирует те характеристики продукта, которые не являются привлекательными для потребителей (табл.). Дальнейшая реализация услуг с такими характеристиками заметно повышает рыночные риски компании. Визуализация проблем однозначно указывает на аспекты продукта, которые требуют немедленного улучшения. По зонам риска в таблице также можно судить и о характере потребностей людей, ранее скрытых от поставщика услуг мобильной связи.

Оиенка средних значений показателя риска

\begin{tabular}{|c|c|c|c|c|c|c|c|c|c|c|c|}
\hline \multirow{2}{*}{ Риск } & \multirow{2}{*}{ Переменная } & \multicolumn{5}{|c|}{ Мужчины } & \multicolumn{5}{|c|}{ Женщины } \\
\hline & & $18-22$ & $23-29$ & $30-39$ & $40-49$ & $50-59$ & $18-22$ & $23-29$ & $30-39$ & $40-49$ & $50-59$ \\
\hline \multirow{8}{*}{$\begin{array}{l}\text { Функ- } \\
\text { цио- } \\
\text { наль- } \\
\text { ный }\end{array}$} & $\begin{array}{l}\text { Качество голосовой } \\
\text { связи }\end{array}$ & 0,35 & 0,45 & 0,45 & 0,25 & 0,40 & 0,50 & 0,45 & 0,35 & 0,35 & 0,30 \\
\hline & $\begin{array}{l}\text { Качество дополнитель- } \\
\text { ных услуг, предостав- } \\
\text { ляемых оператором }\end{array}$ & 0,25 & 0,40 & 0,35 & 0,45 & 0,35 & 0,25 & 0,35 & 0,25 & 0,25 & 0,30 \\
\hline & $\begin{array}{l}\text { Скорость мобильного } \\
\text { интернета }\end{array}$ & 0,35 & 0,50 & 0,50 & 0,50 & 0,75 & 0,35 & 0,50 & 0,25 & 0,50 & 0,80 \\
\hline & \begin{tabular}{|l} 
Специфичность (осо- \\
бость) выгод, получае- \\
мых при пользовании \\
услугами Tele2
\end{tabular} & 0,85 & 0,70 & 0,30 & 0,25 & 0,15 & 0,90 & 0,80 & 0,70 & 0,35 & 0,25 \\
\hline & $\begin{array}{l}\text { Уникальность пред- } \\
\text { лагаемых тарифных } \\
\text { планов }\end{array}$ & 0,85 & 0,80 & 0,55 & 0,60 & 0,45 & 0,75 & 0,80 & 0,90 & 0,45 & 0,65 \\
\hline & $\begin{array}{l}\text { Своевременность появ- } \\
\text { ления на рынке }\end{array}$ & 0 & 0,10 & 0,10 & 0,15 & 0,25 & 0,05 & 0,15 & 0,05 & 0,35 & 0,55 \\
\hline & Доля рынка & 0,85 & 0,50 & 0,75 & 0,80 & 0,90 & 1,00 & 0,75 & 0,75 & 0,85 & 0,85 \\
\hline & $\begin{array}{l}\text { Дифференцирование } \\
\text { услуг }\end{array}$ & 0,45 & 0,25 & 0,15 & 0,25 & 0,25 & 0,25 & 0,20 & 0,30 & 0,35 & 0,25 \\
\hline
\end{tabular}

\section{Baikal Research Journal}

электронный научный журнал Байкальского государственного университета 
Окончание таблицы

\begin{tabular}{|c|c|c|c|c|c|c|c|c|c|c|c|}
\hline \multirow{2}{*}{ Риск } & \multirow{2}{*}{ Переменная } & \multicolumn{5}{|c|}{\begin{tabular}{|c|} 
Мужчины \\
\end{tabular}} & \multicolumn{5}{|c|}{ Женщины } \\
\hline & & $18-22$ & $23-29$ & $30-39$ & $40-49$ & $50-59$ & $18-22$ & $23-29$ & $30-39$ & $40-49$ & $50-59$ \\
\hline & Цена услуги & 0 & 0,05 & 0 & 0 & 0,10 & 0 & 0 & 0 & 0,05 & 0 \\
\hline & Система распределения & 0,55 & 1,00 & 0,70 & 0,35 & 0,20 & 0,90 & 0,45 & 0,35 & 1,00 & 1,00 \\
\hline & $\begin{array}{l}\text { Качество рекламной } \\
\text { кампании }\end{array}$ & 1,00 & 1,00 & 0,85 & 1,00 & 1,00 & 1,00 & 1,00 & 1,00 & 1,00 & 0,80 \\
\hline & Среднее значение & $\mathbf{0 , 5 0}$ & 0,52 & $\mathbf{0 , 4 3}$ & 0,42 & $\mathbf{0 , 4 4}$ & 0,54 & 0,50 & 0,45 & 0,50 & $\mathbf{0 , 5 2}$ \\
\hline \multirow{9}{*}{$\begin{array}{l}\text { Соци- } \\
\text { альный }\end{array}$} & $\begin{array}{l}\text { Принадлежность к } \\
\text { социальной группе }\end{array}$ & 0,05 & 0,60 & 0,75 & 0,75 & 0,95 & 0 & 0,45 & 0,30 & 0,90 & 1,00 \\
\hline & $\begin{array}{l}\text { Установление друже- } \\
\text { ских связей }\end{array}$ & 0,30 & 0,60 & 0,50 & 0,55 & 0,85 & 0,15 & 0,40 & 0,10 & 0,65 & 0,95 \\
\hline & $\begin{array}{l}\text { Самоутверждение в } \\
\text { коллективе }\end{array}$ & 0,80 & 0,45 & 0,40 & 0,05 & 0,15 & 0,95 & 0,75 & 0,95 & 0,35 & 0 \\
\hline & $\begin{array}{l}\text { Уважение к другим } \\
\text { людям }\end{array}$ & 0,65 & 0,30 & 0,50 & 0,25 & 0,20 & 0,80 & 0,25 & 0,90 & 0,30 & 0,65 \\
\hline & $\begin{array}{l}\text { Подчинение / домини- } \\
\text { рование }\end{array}$ & 0,25 & 0,65 & 0,40 & 0,45 & 0,50 & 0,20 & 0,50 & 0,15 & 1,00 & 1,00 \\
\hline & $\begin{array}{l}\text { Отношение к успеху / } \\
\text { неудаче }\end{array}$ & 0,15 & 0,45 & 0,30 & 0,55 & 0,55 & 0,20 & 0,45 & 0,15 & 0,75 & 1,00 \\
\hline & Целеустремленность & 0,10 & 0,55 & 0,35 & 0,70 & 0,45 & 0,05 & 0,65 & 0,30 & 0,45 & 0,50 \\
\hline & Эгоизм / альтруизм & 0,25 & 0,15 & 0,05 & 0,35 & 0,20 & 0,05 & 0,35 & 0,65 & 0,15 & 0 \\
\hline & Среднее значение & $\mathbf{0 , 3 2}$ & $\mathbf{0 , 4 7}$ & $\mathbf{0 , 4 1}$ & 0,46 & 0,48 & 0,30 & 0,48 & 0,44 & $\mathbf{0 , 5 7}$ & $\mathbf{0 , 6 4}$ \\
\hline \multirow{4}{*}{$\begin{array}{l}\text { Эмоци- } \\
\text { ональ- } \\
\text { но-пси- } \\
\text { хологи- } \\
\text { ческий }\end{array}$} & $\begin{array}{l}\text { Отношение человека к } \\
\text { окружающему миру }\end{array}$ & 0,45 & 0,60 & 0,55 & 0,85 & 0,75 & 0,35 & 0,60 & 0,55 & 0,60 & 0,85 \\
\hline & $\begin{array}{l}\text { Отношение человека к } \\
\text { самому себе }\end{array}$ & 0,05 & 0,50 & 0,25 & 0,45 & 0,50 & 0 & 0,30 & 0,30 & 0,30 & 0,30 \\
\hline & $\begin{array}{l}\text { Характер действия } \\
\text { эмоциональных раз- } \\
\text { дражителей } \\
\end{array}$ & 1,00 & 0,95 & 0,80 & 0,90 & 0,85 & 1,00 & 1,00 & 1,00 & 1,00 & 1,00 \\
\hline & Среднее значение & $\mathbf{0 , 5 0}$ & $\mathbf{0 , 6 8}$ & 0,53 & 0,73 & 0,70 & 0,45 & 0,63 & $\mathbf{0 , 6 2}$ & $\mathbf{0 , 6 3}$ & 0,72 \\
\hline \multicolumn{2}{|c|}{$\begin{array}{l}\text { Среднее значение интегрально- } \\
\text { го риска }\end{array}$} & 0,43 & 0,53 & 0,43 & 0,48 & 0,49 & 0,44 & 0,51 & 0,47 & 0,54 & 0,59 \\
\hline
\end{tabular}

$>0,5$ - зона повышенного риска

0,5 - зона граничных значений

$<0,5$ - зона умеренного риска / при $0-$ риск отсутствует

Как видно из приведенных данных (см. табл.), наименее удовлетворены уровнем услуг Tele2 мужчины в возрасте 23-29 лет, а также женщины в возрасте 23-29 лет и старше 40 лет. Значения факторов риска для этих групп респондентов оказывают влияние на интегральный показатель в сторону повышения. Таким образом, полученные данные позволяют определить проблемные характеристики продукта и, соответственно, возможные пути их улучшения, с одной стороны, и проблемные категории потребителей и их неудовлетворенные потребности, с другой.

Представленные результаты исследования дают основание утверждать, что предложенная методика определения скрытых потребностей через оценку факторов риска нового продукта может быть признана рабочей. Следовательно, при принятии менеджментом компании решения о выводе новинки на рынок могут и должны оцениваться характер и уровень риска на основе результатов изучения скрытых / пассивных потребностей, поскольку активизация последних и определяет в конечном итоге степень коммерческого успеха нового продукта.

\section{Baikal Research Journal}




\section{Список использованной литературы}

1. О’Шонесси Дж. Активизация скрытых и пассивных потребностей ваших будущих клиентов [Электронный ресурс] / Дж. О’Шонесси. - Режим доступа : http://www.4p.ru/ main/theory/152318/.

2. Поляков В. В. Доверие как фактор поведения потребителей банковских услуг / В. В. Поляков // Известия Иркутской государственной экономической академии. - 2012. № 5 (85). - С. 61-65.

3. Кленси К. Дж. Моделирование рынка: как спрогнозировать успех нового продукта / К. Дж. Кленси, П. Крейг, М. МакГерри Вольф ; под общ. ред. О. Чернозуба. - М. : Вершина, 2007. -272 c.

4. Школа маркетинга Келлога / под ред. Д. Якобуччи ; пер. с англ. под ред. М. Медникова. - СПб. : Питер, 2004. - С. 134-135.

5. Буторина И. А. Модель потребительского поведения домохозяйств / И. А. Буторина, Н. В. Полякова // Известия Иркутской государственной экономической академии. 2002. 一 № 3 (32). — С. 43-47.

6. Туев В. А. Потребление и проблема оптимизации потребностей / В. А. Туев // Известия Иркутской государственной экономической академии. - 2003. — № 3-4 (36-37). - С. 87-94.

7. Башкирова Е. Тестирование продукта в маркетинговых исследованиях / Е. Башкирова, Е. Данилюк // Практический маркетинг. - 1999. № 8. - С.3-11.

8. Дойль П. Маркетинг, ориентированный на стоимость / П. Дойль ; пер. с англ. под ред. Ю. Н. Каптуревского. - СПб. : Питер, 2001. - 480 с.

9. Курчеева Г. И. Обеспечение маркетинговых исследований новых продуктов / Г. И. Курчеева // Практический маркетинг. - 2012. - № 12. - С. 27-32.

10. Бархатова А. М. Опыт регионального исследования потребителей диетических продуктов / А. М. Бархатова // Известия Иркутской государственной экономической академии. - 2013. - № 1 (87). - С. 77-80.

11. Герасименок В. Ю. Формирование системы риск-менеджмента в венчурном инвестировании / В. Ю. Герасименок // Известия Иркутской государственной экономической академии. - 2014. - № 2 (94). - С. 38-42.

12. Гэд T. 4D брэндинг: взламывая корпоративный код сетевой экономики / Т. Гэд. СПб. : Стокгольм. шк. экономики в Санкт-Петербурге, 2005. - 232 с.

13. Федоров Д. Построение карты восприятия как әффективный инструмент выбора рыночной позиции продукта [Электронный ресурс] / Д. Федоров. - Режим доступа : http:// www.cfin.ru/press/practical/2003-06/02.shtml.

14. Афанасьев А. С. К проблеме измерения хозяйственного риска предприятий реального сектора экономики / А. С. Афанасьев // Известия Иркутской государственной экономической академии. - 2008. - № 3 (59). - С. 87-90.

\section{References}

1. O'Shonessi Dzh. Aktivizatsiya skrytykh i passivnykh potrebnostei vashikh budushchikh klientov [Activation of hidden and passive requirements of your future customers]. Available at: http://www.4p.ru/main/theory/152318/.

2. Polyakov V. V. Confidence as a behavioral factor of banking services consumers. Izvestiya Irkutskoy gosudarstvennoy ekonomicheskoy akademii = Izvestiya of Irkutsk State Economics Academy, 2012, no. 5 (85), pp. 61-65. (In Russian).

3. Clancy K., Krieg P. C., Wolf M. Mc Garry. Market New Products Successfully. Using Simulated Test Market Technology. Lexington Books; New edition edition, 2006. 368 p. (Russ. ed.: Clancy K., Krieg P. C., Wolf M. Mc Garry; Chernozub O. (ed.). Market modelling: how to forecast a new product success. Moscow, Vershina Publ., 2007. 272 p.).

4. Yakobuchchi D. (ed.). Shkola marketinga Kelloga [Kellogg's Marketing School]. Saint Petersburg, Piter Publ., 2004. 398 p.

5. Butorina I. A., Polyakova N. V. Household consumer's behavior model. Izvestiya Irkutskoy gosudarstvennoy ekonomicheskoy akademii = Izvestiya of Irkutsk State Economics Academy, 2002, no. 3 (32), pp. 43-47. (In Russian).

6. Tuyev V. A. Consumption and problem of optimizing requirements. Izvestiya Irkutskoy gosudarstvennoy ekonomicheskoy akademii = Izvestiya of Irkutsk State Economics Academy, 2003, no. 3-4 (36-37), pp. 87-94. (In Russian).

\section{Baikal Research Journal}


7. Bashkirova E., Danilyuk E. Testing products in marketing studies. Prakticheskii marketing $=$ Practical Marketing, 1999, no. 8, pp. 3-11. (In Russian).

8. Doyle Peter. Value-Based Marketing. Marketing Strategies for Corporate Growth and Shareholder Value. John Wiley \& Sons, Inc., 2000. 384 p. (Russ. ed.: Doyle Peter, Kapturevsky Yu. N. (ed.). Cost-Oriented Marketing, Saint Petersburg, Peter. Publ., 2001. 480 p.).

9. Kurcheyeva G. I. Providing Market Research of New Products. Prakticheskii marketing = Practical Marketing, 2012, no. 12, pp. 27-32. (In Russian).

10. Barkhatova A. M. Regional research experience of dietary food consumers. Izvestiya Irkutskoy gosudarstvennoy ekonomicheskoy akademii = Izvestiya of Irkutsk State Economics Academy, 2013, no. 1 (87), pp. 77-80. (In Russian).

11. Gerasimenok V. Yu. Risk management system formation in venture capital investing. Izvestiya Irkutskoy gosudarstvennoy ekonomicheskoy akademii = Izvestiya of Irkutsk State Economics Academy, 2014, no. 2 (94), pp. 38-42. (In Russian).

12. Gad Thomas. 4-D Branding. Cracking the corporate code of the network economy. Financial Times, Prentice Hall, 2000. 256 p. (Russ. ed.: Gad T. 4D brending: vzlamyvaya korporativnyi kod setevoi ekonomiki. Saint Petersburg, Stockholm School of Economics Russia Publ., 2005. 232 p.).

13. Fedorov D. Postroenie karty vospriyatiya kak effektivny instrument vybora rynochnoi pozitsii produkta [Building a perception card as an efficient tool of selecting product market position]. Available at: http://www.cfin.ru/press/practical/2003-06/02.shtml. (In Russian).

14. Afanasyev A. S. On problem of economic risk measurements in businesses of real economy sector. Izvestiya Irkutskoy gosudarstvennoy ekonomicheskoy akademii = Izvestiya of Irkutsk State Economics Academy, 2008, no. 3 (59), pp. 87-90. (In Russian).

\section{Информация об авторах}

Полякова Нина Владимировна - доктор экономических наук, профессор, кафедра менеджмента, маркетинга и сервиса, Байкальский государственный университет, 664003, г. Иркутск, ул. Ленина, 11, e-mail: polyakova@isea.ru.

Залешин Виталий Евгеньевич - магистр менеджмента, г. Иркутск, e-mail: vitalii. zaleshin@gmail.com.

\section{Authors}

Nina V. Polyakova - Doctor habil. (Economics), Professor, Chair of Management, Marketing and Services, Baikal State University, 11 Lenin St., 664003, Irkutsk, Russian Federation; e-mail: polyakova@isea.ru.

Vitaly E. Zaleshin - Master Degree Student, Irkutsk, Russian Federation; e-mail: vitalii. zaleshin@gmail.com.

\section{Библиографическое описание статьи}

Полякова Н. В. Оценка риска вывода новой услуги на рынок на основе выявления скрытых потребностей покупателей / Н. В. Полякова, В. Е. Залешин // Baikal Research Journal. 2016. 一 T. 7, № 1. — DOI : 10.17150/2411-6262.2016.7(1).9.

\section{Reference to article}

Polyakova N. V., Zaleshin V. E. Assessing risks of a new service market launch on the basis of identifying customers' hidden requirements. Baikal Research Journal, 2016, vol. 7, no. 1. DOI: 10.17150/2411-6262.2016.7(1).9. (In Russian).

\section{Baikal Research Journal}

